\title{
PERGAMON
}

www.elsevier.com/locate/watres

\section{ESTIMATION OF SLUDGE SEDIMENTATION PARAMETERS FROM SINGLE BATCH SETTLING CURVES}

\author{
ALEXIS VANDERHASSELT ${ }^{1 \mathrm{M}}$ and PETER A. VANROLLEGHEM ${ }^{2 * M}$ \\ ${ }^{1}$ Laboratory of Microbial Ecology, University Gent, Coupure Links 653, B-9000 Gent, Belgium and \\ ${ }^{2}$ BIOMATH Department, University Gent, Coupure Links 653, B-9000 Gent, Belgium
}

(First received 1 December 1998; accepted in revised form 1 April 1999)

\begin{abstract}
In this paper a comparison is made between two means of obtaining the parameters for the settling velocity models that are at the core of the solid flux theory: (i) the traditional approach using zone settling velocity $\left(V_{\mathrm{ZS}}\right)$ data obtained from a dilution experiment and (ii) a new direct parameter estimation method relying on a single batch settling curve (SBSC). For four distinct sludges, settling curves were recorded at different sludge concentrations $(X)$ and the Vesilind parameters were calculated in the traditional way. The value of the resulting model was evaluated by cross-validating it on its ability to describe complete SBSC's. Provided the dynamics of the sludge blanket descent were moderate a settler model incorporating these traditional Vesilind parameters could reasonably match the experimental batch settling curves. However, when the dynamics of the sludge blanket descent were fast, the Vesilind model failed. It was tried whether other settling velocity models could result in better fits to the SBSC. Here, the Cho model turned out to be the most effective one. When cross-validating the Cho model on the dilution experiment $V_{\mathrm{ZS}}$-data, however, it was found to be less performing than the Vesilind model in describing the relationship between $V_{\mathrm{ZS}}$ and $X$. The fact that the Vesilind model is superior to the Cho model in describing such relationships, while the Cho model is better in describing complete settling curves, clearly points out that current settling models are still very empirical in nature. An important finding was that with all settling velocity models tested, practical identifiability problems appeared, indicating the need for better experimental designs. Finally, the flux curves associated with the SBSC-estimated Cho parameters were compared with the traditional Vesilind flux curves. Although both types of flux curves generally showed similar trends, the reliability of SBSCbased flux curve predictions is at present insufficient to warrant replacement of the traditional estimation of settling characteristics. (C) 1999 Elsevier Science Ltd. All rights reserved
\end{abstract}

Key words - activated sludge, batch settling curves, flux curves, parameter estimation, sedimentation, settling models

NOMENCLATURE

$\begin{array}{ll}A & \text { surface of the clarifier }\left(\mathrm{m}^{2}\right) \\ V_{0} & \text { Vesilind maximum settling velocity }(\mathrm{m} / \mathrm{h})\end{array}$

$k^{\prime} \quad$ Cho parameter $\left(\mathrm{kg} / \mathrm{m}^{2} \mathrm{~h}\right)$

$n \quad$ Vesilind parameter $\left(\mathrm{m}^{3} / \mathrm{kg}\right)$

$n^{\prime} \quad$ Cho parameter $\left(\mathrm{m}^{3} / \mathrm{kg}\right)$

$r_{\mathrm{h}} \quad$ Takacs settling parameter associated with the hindered settling component of the settling velocity equation $\left(\mathrm{m}^{3} / \mathrm{kg}\right)$

$r_{\mathrm{p}} \quad$ Takacs settling parameter associated with the low concentration and slowly settling component of the suspension $\left(\mathrm{m}^{3} / \mathrm{kg}\right)$

SBSC Single Batch Settling Curve

$V_{0}{ }^{\prime} \quad$ Takacs maximum theoretical settling velocity $(\mathrm{m} / \mathrm{h})$

$V_{\text {ZS }} \quad$ stirred zone settling velocity $(\mathrm{m} / \mathrm{h})$

$X \quad$ sludge concentration $\left(\mathrm{kg} / \mathrm{m}^{3}\right)$

$X_{\min } \quad$ minimum attainable sludge concentration $\left(\mathrm{kg} / \mathrm{m}^{3}\right)$

*Author to whom all correspondence should be addressed. Tel.: +32-9-264-5932; fax: +32-9-223-4941; e-mail: peter.vanrolleghem@rug.ac.be
$\begin{array}{ll}X_{\mathrm{t}} & \begin{array}{l}\text { threshold sludge concentration for activation of } \\ \text { the minimal flux restriction }\end{array} \\ Q_{\mathrm{u}} & \text { underflow flow rate }\left(\mathrm{m}^{3} / \mathrm{h}\right)\end{array}$

\section{INTRODUCTION}

The design and operation of secondary clarifiers is commonly based on the solid flux theory (Ong, 1992; Daigger, 1995). The basic data required for the application of this theory can be obtained from multiple batch tests by which the stirred zone settling velocities $\left(V_{\mathrm{ZS}}\right)$ over a range of sludge concentrations $(X)$ are measured (dilution experiment). The relationship between $X$ and $V_{\mathrm{ZS}}$ is most often characterised by the Vesilind equation [Eq. (1)] which contains two parameters: $V_{0}$ and $n$. The key underlying assumption is that the settling velocity is only dependent on the local sludge concentration. The Vesilind parameters can then be used to con- 
struct the flux curve which is the key input of the solid flux theory. Obtaining the Vesilind parameters by a dilution experiment is unfortunately time consuming and labour intensive and can result in scattered data (Ekama et al., 1997). An alternative approach consists of linking sludge volume indices as SVI, DSVI and SSVI to $V_{0}$ and $n$ through empirical functions (Daigger, 1995; Ozinsky and Ekama, 1995). This linking is done on the basis of extensive historical data sets on sludge volume indices and Vesilind parameters. These relationships have to be used with care because the $V_{Z S}$ is influenced by factors not incorporated in the sludge concentration and sludge volume indices (Ozinsky and Ekama, 1995). A more structural analysis of the different SVI indices allowed Bye and Dold (1998) to seriously question the validity of any correlation between Vesilind parameters and sludge volume indices. This leaves operators and researchers at present with the choice between a labour intensive and a non-unconditional approach.

Cacossa and Vaccari (1994) and Vanrolleghem et al. (1996) successfully fitted one-dimensional settling models to single batch settling curves (SBSC). Hence, batch settling curve based parameter estimation appears to have the potential of being a good means of efficiently obtaining information on sludge settling characteristics for use in the solid flux theory. However, each of the above studies was restricted to one specific kind of sludge and in neither of the mentioned papers fluxes calculated with the obtained parameter estimates were compared against fluxes obtained with the traditional approach using dilution experiment $V_{\mathrm{ZS}}$ 's.

Consequently, the work that resulted in this paper focused on the ability of SBSC-based characterisation of settling velocity models for use in solid flux theory instead of the method based on dilution experiment $V_{\mathrm{ZS}}$-data. Attention was particularly paid to the practical identifiability of the parameters from such SBSC data sets and to the comparison between the resulting flux curves and the flux curves obtained from traditional interpretation of dilution experiment $V_{\mathrm{ZS}}$-data sets.

\section{METHODS}

\section{Experimental layout}

The recently developed Settlometer (Vanrolleghem et al., 1996; commercially available from Applitek nv, Deinze, Belgium) allows to automatically record complete batch sludge settling curves, and quantify the initial settling velocity $\left(V_{\mathrm{ZS}}\right)$ and the stirred sludge volume (SSV). Sludge settles in batch mode in a settling column that has a height of $70 \mathrm{~cm}$ and a diameter of $14 \mathrm{~cm}$, and is equiped with a stirrer $(0.3 \mathrm{rpm})$.

Four different kinds of sludge (Table 1) were brought to the laboratory where they were aerated over night before use in an experiment. In this way sludge with stable sedimentation characteristics was obtained (Vanderhasselt and Verstraete, 1999). The storage and settling experiments were performed at room temperature.

Each sludge was thickened for $1 \mathrm{~h}$ and subsequently pumped into the Settlometer where it was allowed to settle for $35 \mathrm{~min}$. Next, the sludge was rehomogenised by shortly mixing with air. To set up an experiment at a lower sludge concentration, part of the sludge in the device was subsequently replaced by supernatant and a new settling curve was recorded. The amount of sludge to be removed at each dilution step was calculated in such a way that the obtained sludge concentrations were more or less equidistant. This procedure was repeated until six settling curves were recorded. Further, care was taken to ensure that at the highest sludge concentration applied still a substantial descent of the sludge blanket occurred, while at the lowest concentration, still a sharp sludge blanket/water interface could be detected. The suspended solids concentration was determined by centrifugation (NBN 366.01, 1956). From the dilution experiment described above, the Vesilind parameters were obtained by linear least-squares regression of the $\log \left(V_{\mathrm{ZS}}\right)$ against the sludge concentration. Parameters obtained with this approach will be referred to as the traditional Vesilind parameters.

\section{Modelling layout}

In the past, quite a number of settling velocity models have been presented in literature (Vesilind, 1968; Dick and Young, 1972; Takacs et al., 1991; Otterpohl and Freund, 1992; Cho et al., 1993; Watts et al., 1996). On lab settler data Grijspeerdt et al. (1995) identified the Takacs et al. (1991) model [Eq. (2)] to be the best. Watts et al. (1996) stated that for the prediction of sludge blanket dynamics the Takacs model [Eq. (2)] can be simplified to the Vesilind model [Eq. (1)]. The latter model clearly is the most frequently used (Ong, 1992; Ozinsky and Ekama, 1995; Bye and Dold, 1998). Cho et al. (1993) also advised that the number of parameters in a model should be limited to two in order to be simple enough for application in practice. In view of these reflections the Vesilind model was identified as the most interesting to start with. Later in the study the two-parameter Cho settling velocity model [Eq. (3)] was applied as well.

$$
V_{\mathrm{s}}=V_{0} \mathrm{e}^{-n X}
$$

$$
V_{\mathrm{s}}=V_{0}^{\prime}\left(\mathrm{e}^{-r_{\mathrm{h}}\left(X-X_{\min }\right)}-\mathrm{e}^{-r_{\mathrm{p}}\left(X-X_{\min }\right)}\right)
$$

$$
V_{\mathrm{s}}=k^{\prime} \frac{\mathrm{e}^{-n^{\prime} X}}{X} .
$$

Batch settling experiments were thought to be an interesting information source for parameter estimation as the data are the result of only the physical properties of the

Table 1. "Traditional " Vesilind parameters for the different sludges

\begin{tabular}{lccccc}
\hline Sludge & Concentration range $\left(\mathrm{kg} / \mathrm{m}^{3}\right)$ & $\mathrm{V}_{\text {ZS }}$ range $(\mathrm{m} / \mathrm{h})$ & $V_{0}(\mathrm{~m} / \mathrm{h})$ & $n\left(\mathrm{~m}^{3} / \mathrm{kg}\right)$ & Correlation coefficient \\
\hline B & $15.6-3.0$ & $0.5-3.6$ & 10.3 & 0.19 & 0.9693 \\
D & $4.1-0.5$ & $0.4-4.7$ & 5.5 & 0.64 & 0.9712 \\
O & $14-2.2$ & $0.8-9.1$ & 12.2 & 0.21 & 0.9677 \\
P & $6.6-1.0$ & $0.7-3.2$ & 6.9 & 0.36 & 0.9854 \\
\hline
\end{tabular}




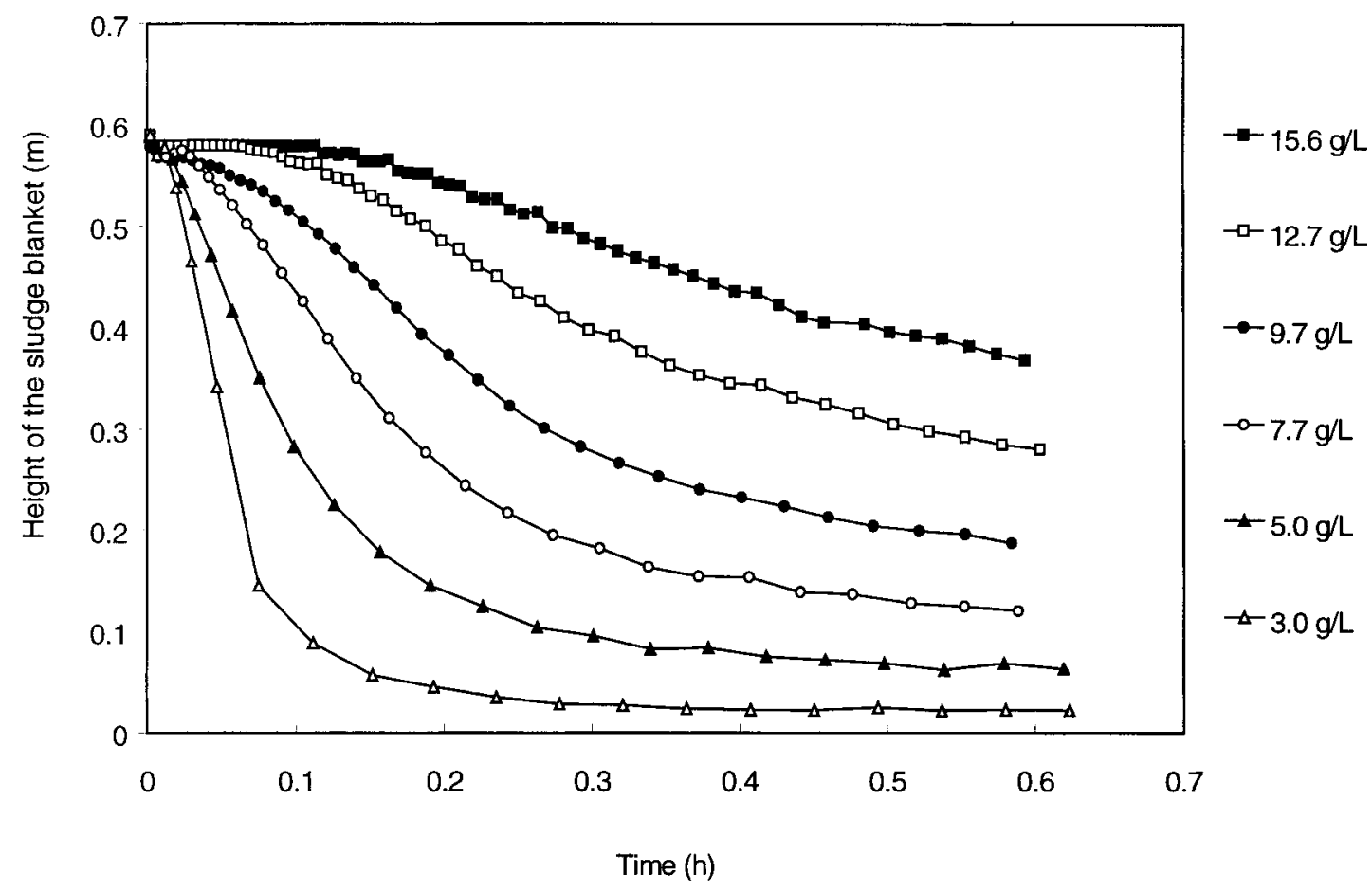

Fig. 1. Settling curves from the dilution experiment with the B sludge.

measuring device and the settling properties of the sludge The settling device can be assumed to have constant properties. There are no bulk flows in the batch-wise operating device and, consequently, no associated momentums that influence the movement of the sludge blanket. Additionally, model calibration problems such as the location of the influent layer (Watts et al., 1996; Ekama et al., 1997) or the determination of short circuit flows from the feedlayer to the sludge recycle (Dupont and Dahl, 1995) are avoided.

The settling velocity models were incorporated in a settler model discretisised into 49 horizontal layers of equal volume. This discretisation can be seen as a finite difference approximation of the underlying partial differential equation and was introduced by Stenstrom (1975). The large number of layers was chosen to resolve the detailed behaviour of the settling process as recommended by Jeppsson and Diehl (1996). Further, this number of layers is required to obtain a resolution that is similar to the accuracy of the measured settling curve. The layer structure was combined with the minimal flux restriction that restrains the gravitational flux from a certain layer to the layer below to the minimal gravitational flux of both layers (Stenstrom, 1975). Vitasovic (1989) activated this restriction only when the sludge concentration reached a certain minimum concentration $\left(X_{\mathrm{t}}\right)$, i.e. $3 \mathrm{~kg} / \mathrm{m}^{3}$. Ekama et al. (1997) identify this restriction as being necessary for numerical stability of the simulation. However, there is also physical ground to this concept: a layer can not unconditionally discharge sludge to a layer in which there is already a substantial amount of sludge. To avoid that $X_{\mathrm{t}}$ would influence the result without being actually estimated, it was decided to activate the minimal flux restriction throughout the whole concentration region $\left(X_{\mathrm{t}}=0 \mathrm{~kg} /\right.$ $\mathrm{m}^{3}$ ) for all sludges considered. This does not pose a problem for the description of batch settling data because the sludge concentrations that determine the height of the sludge blanket are relatively high and the sludge concentration increases continuously from top to bottom.
Further, for Vesilind and Cho based settler models these sludge concentrations are located in the descending part of the flux curve, so the minimal flux restriction will always be active regardless the fact whether $X_{\mathrm{t}}$ is equal to 0 or $3 \mathrm{~kg} / \mathrm{m}^{3}$.

The height of the sludge blanket was defined as the location of the uppermost layer with a sludge concentration higher than a certain threshold. Vitasovic (1986) and Vanrolleghem et al. (1996) used $3 \mathrm{~kg} / \mathrm{m}^{3}$ as the threshold. From a numerical simulation with different sludge blanket thresholds it was found that the definition of this threshold is not critical. Evidently, this statement only holds as long as the threshold sludge concentration is lower than the sludge concentration at the start of the experiment. For practical reasons this sludge blanket threshold was therefore set to $1 \mathrm{~kg} / \mathrm{m}^{3}$, being lower than the initial sludge concentration of all modelled experiments.

When a settling curve is recorded (Fig. 1) one observes that some start-up phenomena take place before the descent of the blanket starts. To incorporate also these phenomena in the batch settling model, the settling velocity model was slightly changed. This was done by multiplying the settling velocity model with an on-off term. This term is 0 when the simulation time $(t)$ is smaller than the start-up time $\left(T_{\mathrm{st}}\right)$ and 1 when it is larger than $T_{\mathrm{st}}$. In this way the start-up phenomena are incorporated in the model without affecting the settling part itself. Moreover, this method has the advantage that the settling velocity model is activated as soon as the blanket starts to descend.

\section{RESULTS}

Before starting the parameter estimation, the clarifier model was evaluated from a theoretical point of view. Analysis of the concentration profiles 

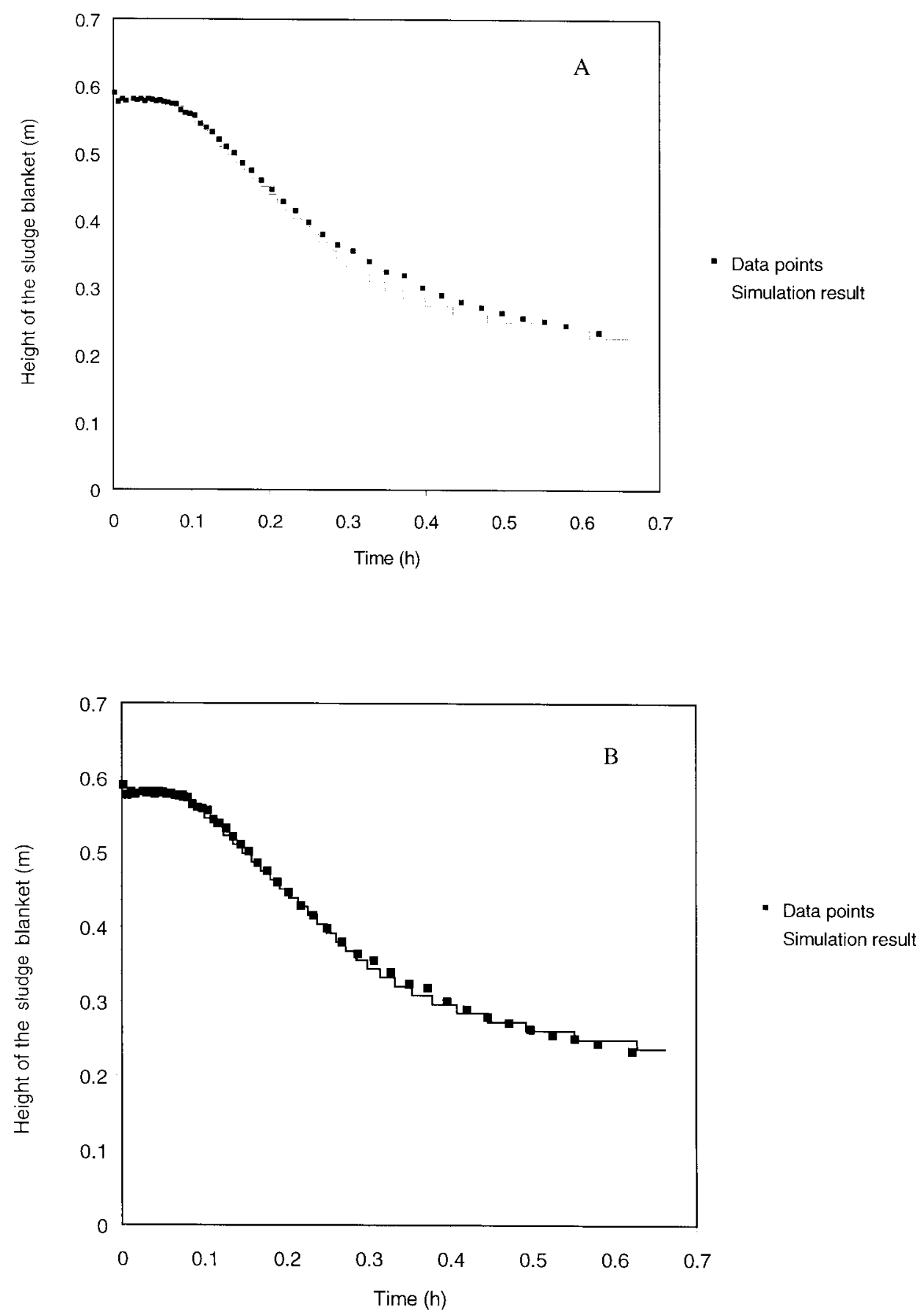

Fig. 2. Data and model output from the Vesilind based model for the $\mathrm{O}$ sludge at $11.0 \mathrm{~kg} / \mathrm{m}^{3}$. (A) Traditional calibration on set of $V_{\mathrm{ZS}}$. (B) Optimisation result $V_{0}=13.1 \mathrm{~m} / \mathrm{h}, n=0.219 \mathrm{~m}^{3} / \mathrm{kg}$, $T_{\mathrm{st}}=6.70 \mathrm{E}-02 \mathrm{~h}$.

showed that the evolution of the sludge blanket in the zone settling phase is determined only by the initial sludge concentration. Only when the settling curve starts to bend (i.e. when the settling velocity decreases) higher concentrations have a significant impact on the evolution of the sludge blanket. Hence, only from that time instant onwards, the data contain information on more than one sludge concentration. Therefore, it is postulated to be an essential experimental condition that the obtained settling curve shows sufficient amount of bending before reliable parameter estimation can be performed on a SBSC. This statement can be supported from a mathematical point of view: there is 

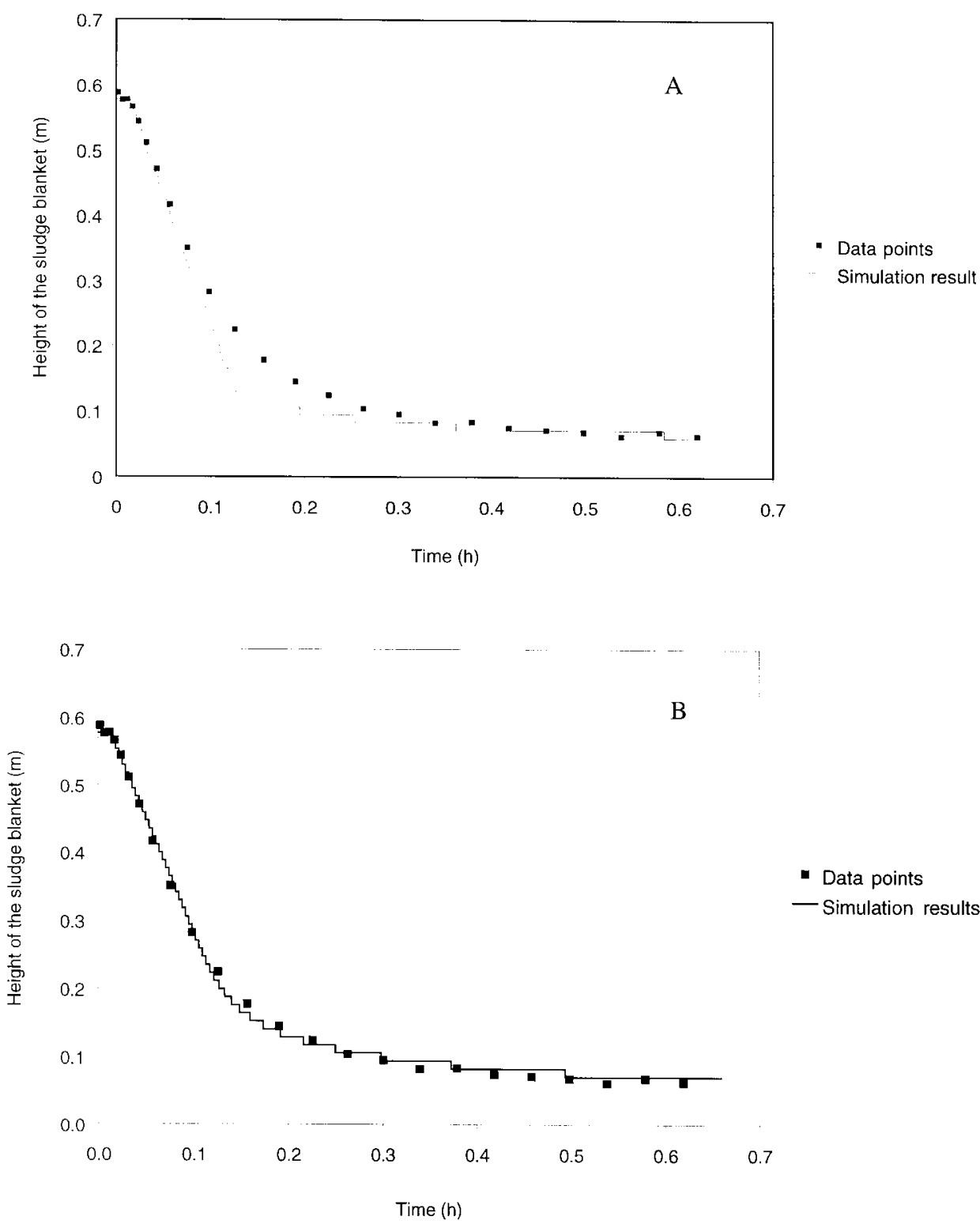

Fig. 3. Data and model output for the B sludge at $5.0 \mathrm{~kg} / \mathrm{m}^{3}$. (A) For the Vesilind based model with traditional calibration on set of $V_{\mathrm{ZS}}$. (B) Optimisation results of the Cho based model $k^{\prime}=29.6 \mathrm{~kg} /$ $\mathrm{h} \mathrm{m}{ }^{2}, n^{\prime}=0.12 \mathrm{~m}^{3} / \mathrm{kg}, T_{\mathrm{st}}=1.10 \mathrm{E}-02$.

only one additional parameter needed to describe a straight line once one point (the initial height at the starting of the sedimentation phase) of the curve is known.

Settling curves at different sludge concentrations were recorded for each sludge. As an example the resulting settling curves for the $\mathrm{B}$ sludge are depicted in Fig. 1. For the different sludges, the traditional Vesilind parameters resulting from such dilution experiment are summarised in Table 1 . Looking at the parameter values one can conclude that sludges with good settling properties $(\mathrm{B}, \mathrm{O})$ as well as poor settling sludges $(\mathrm{D}, \mathrm{P})$ were included in the experimental plan.
Cross-validation 1: traditional Vesilind parameters to single batch settling curve

For each experimental data set, the batch settler model was solved using the traditional Vesilind parameters. For $T_{\mathrm{st}}$, a value was used that gave a minimal squared error (SSE) between the simulation result and the data. Provided that the dynamics in the sludge blanket were rather slow, reasonable agreement (and, thus, cross-validation) could be obtained between the data and the simulation results e.g. Fig. 2(A). Still, when the zone settling phase is ending and the settling curve starts to bend [in Fig. 2(A) between $t=0.2$ and $t=0.5 \mathrm{~h}$ ] a small 


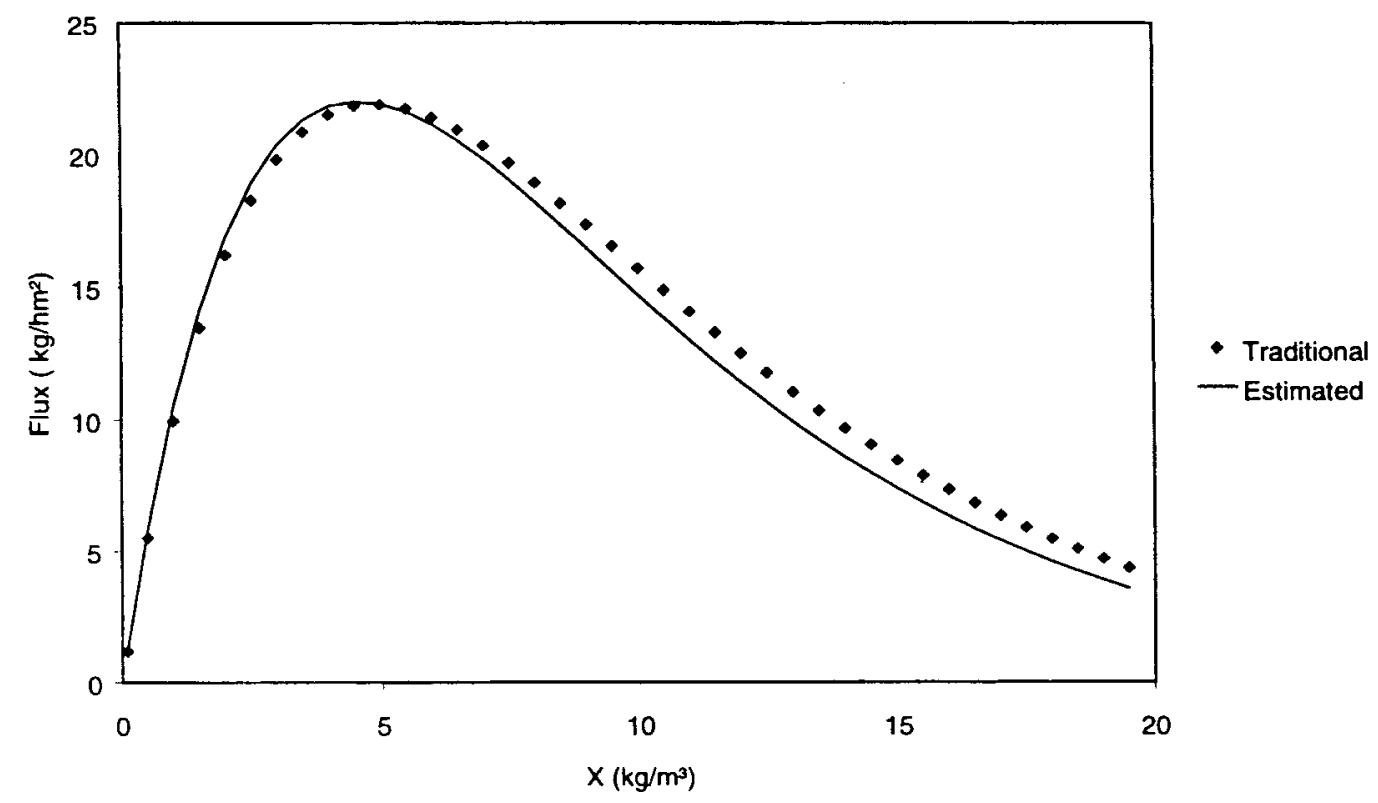

Fig. 4. Flux curves for the traditional and the SBSC $\left(X=11.0 \mathrm{~kg} / \mathrm{m}^{3}\right)$ estimated Vesilind parameters for the O sludge.

discrepancy appears between the data and the simulation result. For settling curves with faster dynamics (higher $V_{\mathrm{ZS}}$ ), e.g. Fig. 3(A), it becomes obvious that the discrepancy becomes bigger for this transition zone. Still, although the model (with Vesilind settling velocity model and parameters obtained from a dilution experiment) is not able to predict a solids profile that allows a smooth transition between the zone settling phase and the compaction phase, it is able to accurately describe the zone settling phase and the final height of the blanket. Similar trends could be observed with the other sludges. It can be concluded that the model allows to adequately describe slow dynamic batch settling curves when it is calibrated with parameters from a dilution experiment.

Parameter estimation from a slow dynamic single batch settling curve

For the estimation from a SBSC approach, a direction set algorithm (Brent, 1973) was used to find the parameters $\left(V_{0}, n\right.$ and $\left.T_{\text {st }}\right)$ that would result in a minimal SSE between the observed data and the simulation results. For the data of Fig. 2(A) this resulted in the fit depicted in Fig. 2(B). As can be seen for this slow dynamic SBSC, the obtained fit is rather good. The fit in Fig. 2(B) is better than the fit of Fig. 2(A). This is as expected because the simulated curve in Fig. 2(A) is not the result of a parameter estimation exercise, but the result of a cross-validation of parameters obtained from the dilution experiment. Further, the estimated Vesilind parameters $\left(V_{0}=13.1 ; n=0.22\right)$ can be considered rather close to the ones obtained from the traditional determination $\left(V_{0}=10.3 ; n=0.19\right)$.
Although the above is important for the quality assurance of lab experiments, it is the flux curves in which practitioners are interested. In order to evaluate this, the flux curves for both parameter sets (traditional vs SBSC estimation) were plotted against each other (Fig. 4). As can be seen from this figure, both curves are rather close to each other, although in the upper concentration region differences run up to $17 \%$. Fig. 4 can also be considered as a crossvalidation from the SBSC approach to the dilution approach. In the present case, the cross-validation result is reasonable. However, in other cases (data not shown) the results were less.

\section{Evaluation of practical identifiability}

When estimating parameters it is important to check whether the available data are informative enough to give unique values to the model's parameters. When the information content of a data set is too low, it is possible that different parameter sets can be found giving equal fit. This practical identifiability phenomenon surfaces when different estimates are found when the parameter search algorithm is started from different initial parameter guesses. In order to assess eventual practical identification problems in this application, the sum of squared errors was calculated for a large number of parameter sets in a parameter subspace. In the resulting Fig. 5 one observes no sharp minima but rather broad valleys. This clearly points towards identification problems, i.e. it is not straightforward to find the lowest sum of squared errors, leading to the best parameter set. This identifiability problem was further confirmed by tests that were conducted in which the search algorithm was started from 


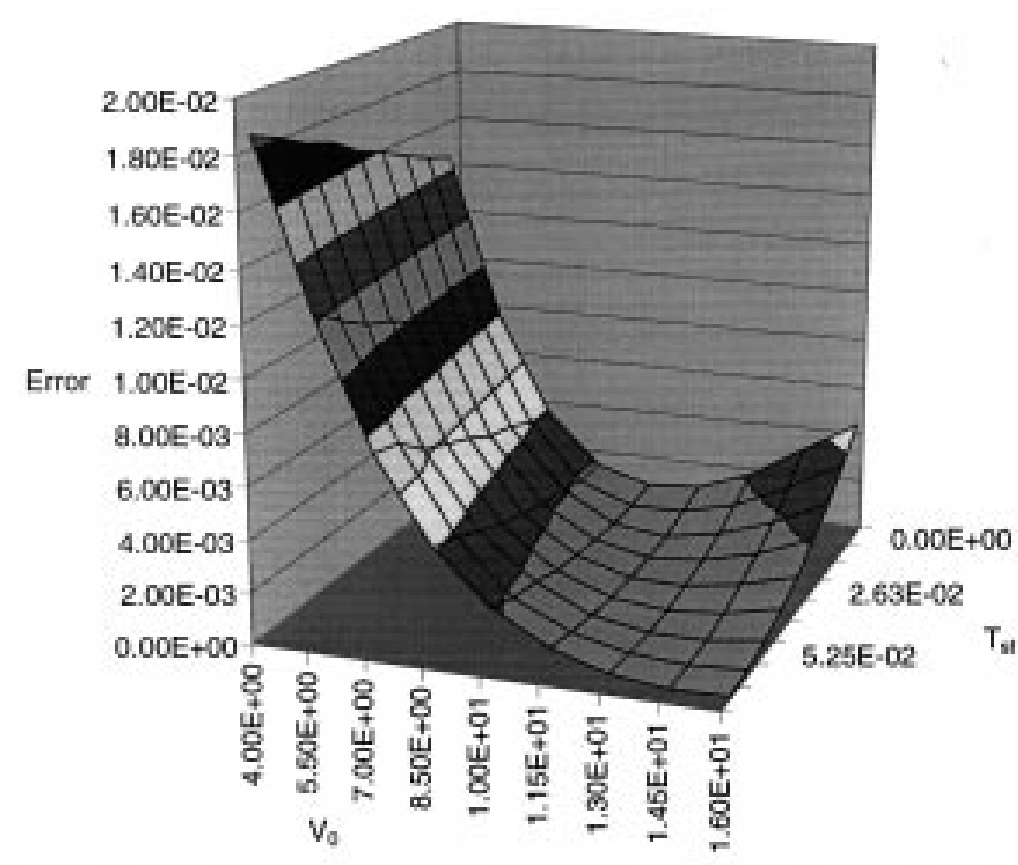

1.80E-02-2.00E-02

[1.60E-02-1.00E-02

口1.40E-02-1,60E-02

E1.20E-02-1,40E-02

1,00E-02-1,20E-02

E,00E-03-1,00E-02

D6.00E-03-8.00E-03

口4.00E-03-6.00E-03

E2.00E-03-4.00E-03

口 $0.00 \mathrm{E}+00-2.00 \mathrm{E}-03$

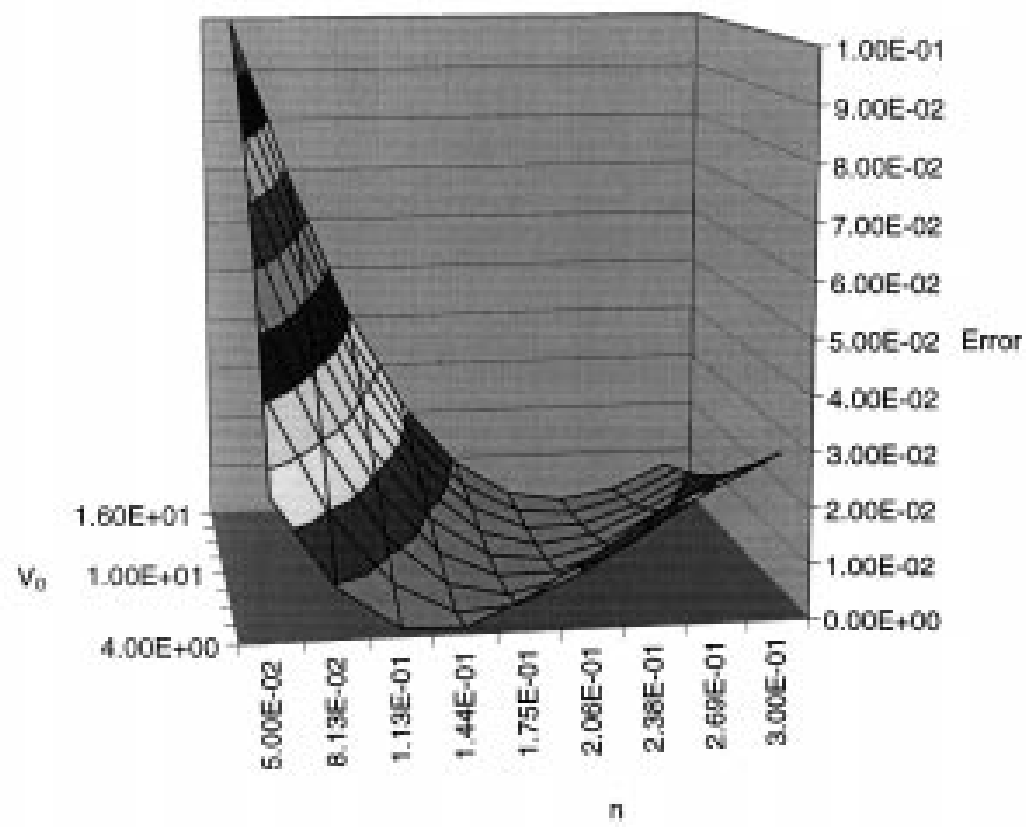

ㅁ.00E-02-1.00E-01

- 8.00E-02-9.00E-02

- $7.00 \mathrm{E}-02 \cdot 8.00 \mathrm{E}-02$

- 6.00E-02-7.00E-02

口5.00E-02-6.00E-02

- 4.00E-02-5.00E-02

D3.00E-02-4.00E-02

口2.00E-02-3.00E-02

-1.00E-02-2.00E-02

$\square_{0.00 E * 00-1.00 E-02}$

Fig. 5. Simulation error as function of different parameter combinations for $\mathrm{O}$ sludge at $11.0 \mathrm{~kg} / \mathrm{m}^{3}$. Top: $n=0.219 \mathrm{~m}^{3} / \mathrm{kg}$. Bottom: $T_{\mathrm{st}}=0.067 \mathrm{~h}$.

different initial parameter sets, resulting in different optimisation results.

As the SBSC approach was not successful in finding unique parameter values, it was evaluated whether a multiple response fitting method as used by De heyder et al. (1997) could provide a solution. In this approach, parameters are estimated using different settling curves obtained with different concentrations of one kind of sludge. The identification is then based on the fact that each settling curve contains different information due to the different initial sludge concentration and the fact that for all curves the same Vesilind parameters must hold. Note, however, that $T_{\mathrm{st}}$ is dependent on $V_{\mathrm{ZS}}$ (Vanderhasselt et al., 1999) and hence, it is different for each curve. Therefore, an optimal $T_{\text {st }}$ value was determined for each settling curve. Subsequently, for each settling curve the sum of squared errors was calculated in the $V_{0} / n$ parameter space. The resulting error surfaces were quite similar in shape 


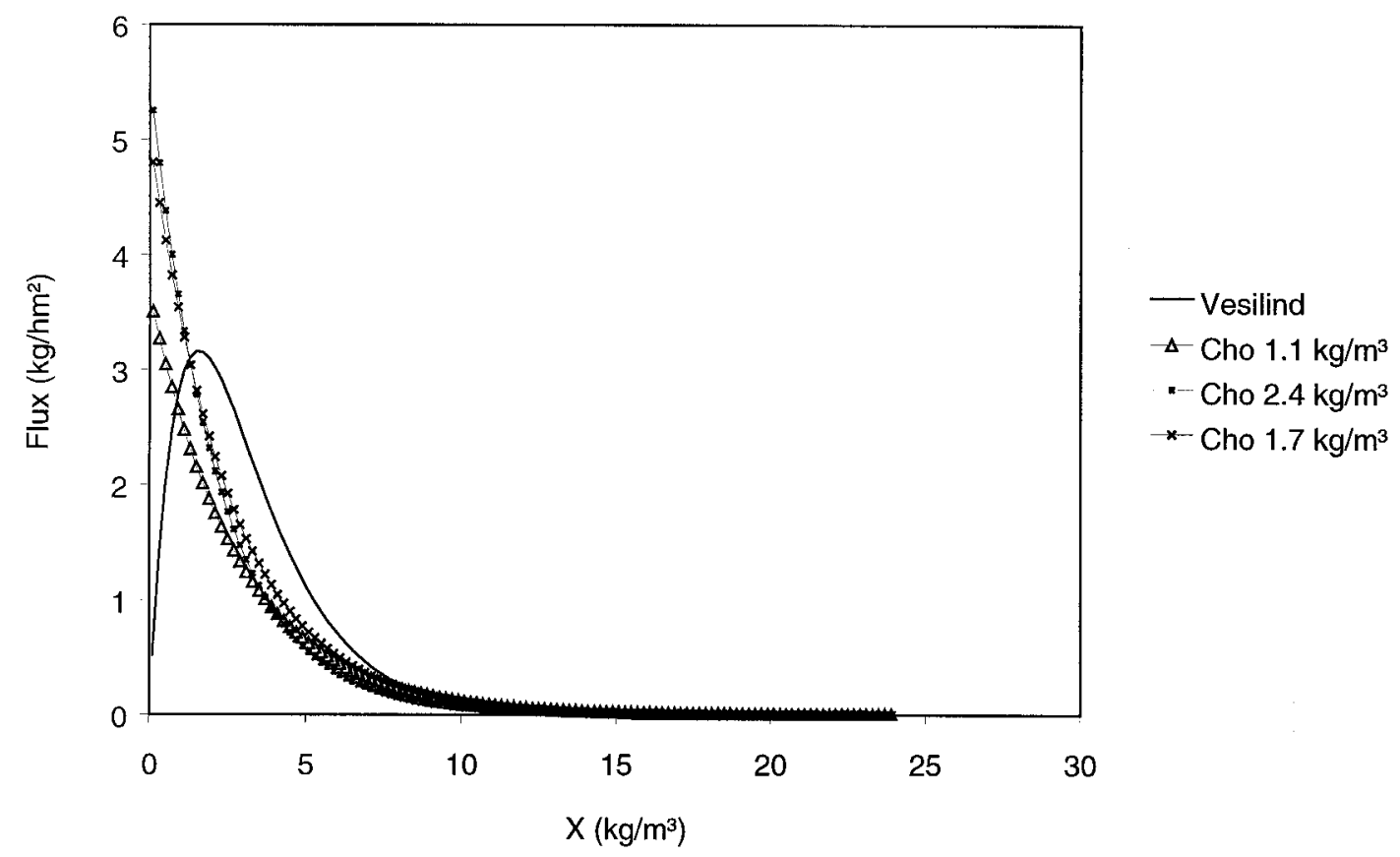

Fig. 6. Flux curves for D sludge, calculated with the Vesilind parameters traditionally calibrated on a set of $V_{\mathrm{ZS}}$ 's and Cho parameters obtained from different SBSC's.

as the one at the bottom Fig. 5. Combining these surfaces did not result in a graph with a sharp minimum. Consequently, multiple response fitting was not successful in solving the identifiability problem.

Parameter estimation from a fast dynamic single batch settling curve

For sedimentation curves with faster dynamics it was not possible to obtain Vesilind parameters which were able to describe the curve adequately. In particular, no parameter set could be found that was able to describe the transition between the zone settling phase and the compression phase substantially better than the traditional Vesilind parameters [Fig. 3(A)].

Because this Vesilind approach was not fully successful, alternative settling velocity models as proposed by Takacs et al. (1991) and Watts et al. (1996) were evaluated. Neither of these models was able to describe the data substantially better than the Vesilind model.

A hybrid Vesilind settling velocity model [Eq. (3)] that was proposed by Cho et al. (1993) to describe the relation between $V_{\mathrm{ZS}}$ and $X$ in dilution experiments, was tested subsequently. It is important to realise that special attention must be directed to the lower concentration region when this Cho model is used to calculate settling velocities: when the sludge concentration reaches zero, the settling velocity goes to infinity, which is not physically possible. In order to prevent this, a threshold concentration below which the settling velocity is set to zero was incorporated. Arbitrarily this constant was set at $0.1 \mathrm{~kg} / \mathrm{m}^{3}$. The precise value of this threshold was identified not to be critical for this particular concentration. One should note the correspondence between this threshold concentration and the nonsettleable fraction $X_{\min }$ in the Takacs settling velocity model.

Among all models tested, the Cho model gave the best fits to the settling curves under consideration, i.e. it gave the lowest SSE. The better ability of the Cho model to describe complete batch settling curves is obvious if one compares the fit of the Vesilind model [Fig. 3(A)] with the one of the Cho model [Fig. 3(B)]. While the Cho model provided better fits indicating its superior structural flexibility, still identifiability problems similar to the problems observed with the Vesilind model were encountered.

In Fig. 6 the Cho flux curves calculated with parameters obtained from different SBCS at different concentrations are depicted. Next to the Cho flux curves the traditional Vesilind flux curve is depicted. Considering Fig. 6, it is clear that the fluxes obtained with the SBSC-estimated parameters should be used with precaution as there can be some difference between the flux curves obtained from parameters estimated from SBSC's at different sludge concentrations. For the D sludge as well as for the other sludges the highest flux curves were obtained with parameters estimated from the settling curve with the highest initial sludge concentration. In the higher sludge concentration region the Cho flux curves with parameters obtained from 


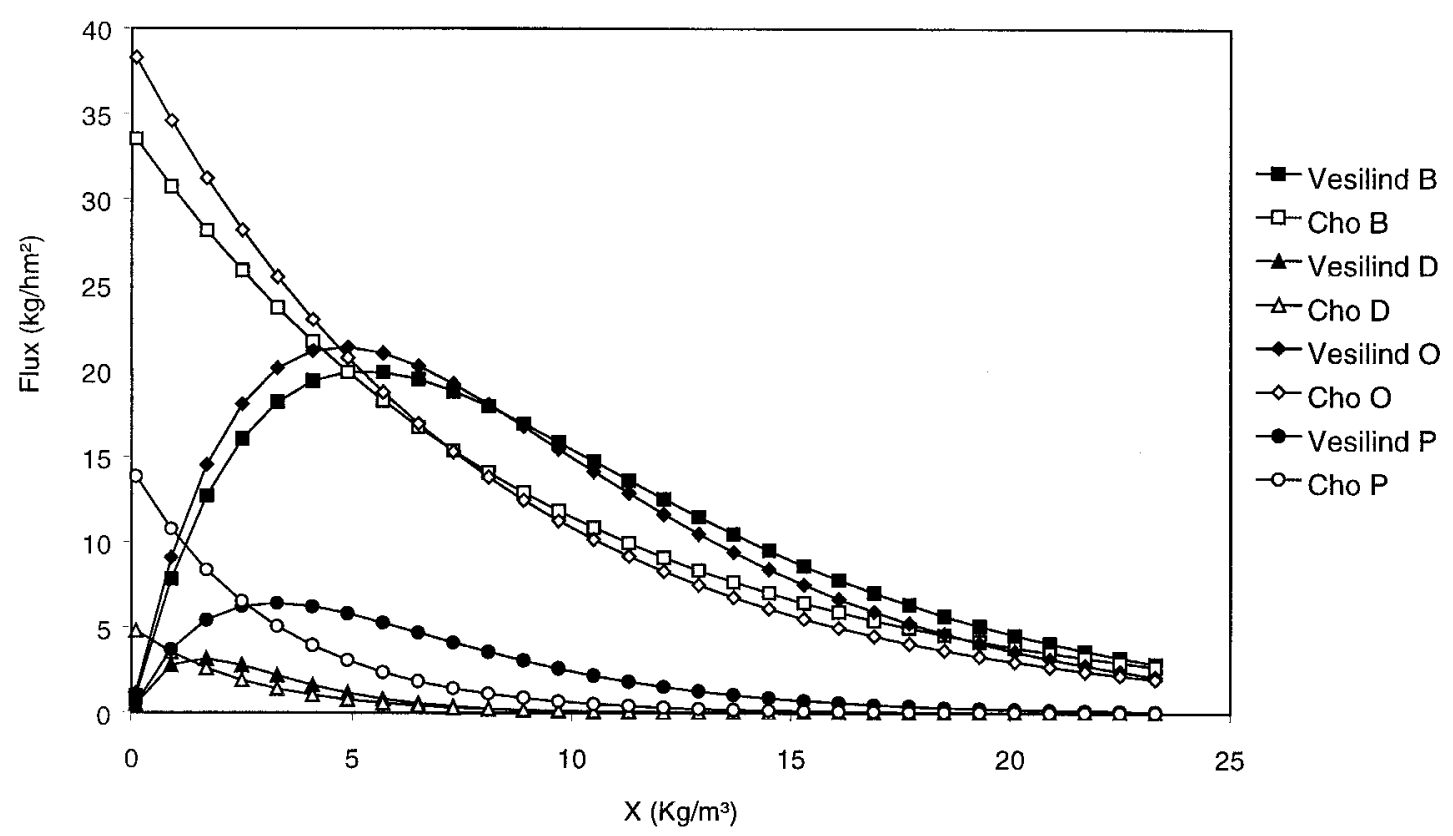

Fig. 7. Flux curves for the different sludges according to the Vesilind model traditionally calibrated on a set of $V_{\mathrm{ZS}}$ 's (closed symbols) and the Cho model obtained from the middle concentration SBSC's (open symbols).

the SBSC approach were situated below the traditional Vesilind flux curve.

For each sludge the flux curves with the parameters obtained from the middle of the three selected sludge concentrations are plotted in Fig. 7. It becomes clear that the fluxes resulting from the parameter estimation follow the same trend as observed with the Vesilind flux curves obtained from dilution experiments. Sludges that have high traditional Vesilind flux curves like $\mathrm{B}$ and $\mathrm{O}$ also have high Cho-from-SBSC flux curves. Sludges with low traditional flux curves like D and P have corresponding low Cho flux curves.

Cross-validation 2: Cho SBSC-estimated parameters to dilution experiment $V_{Z S}$

In order to further investigate the validity of the Cho model, it was evaluated whether the Cho par-

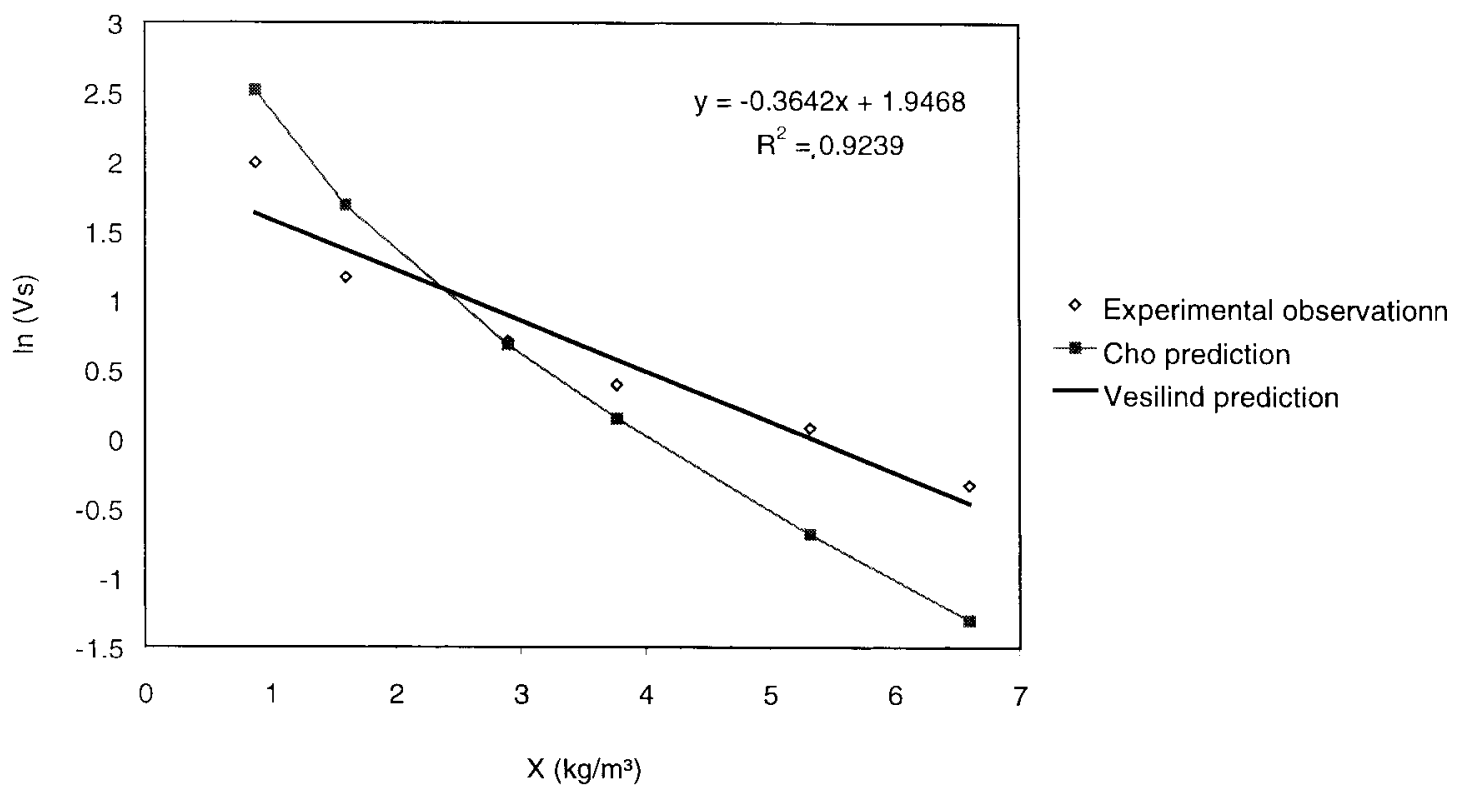

Fig. 8. Natural logarithm of the $V_{\mathrm{ZS}}$ in function of the $\mathrm{P}$ sludge concentration. 
ameters resulting from the SBSC approach could describe the $X / V_{\mathrm{ZS}}$ relationships as observed in the dilution experiment (cross-validation). To this end the natural logarithm of the observed and parameter predicted $V_{\mathrm{ZS}}$ were plotted as function of the sludge concentration, e.g. Fig. 8. The Cho parameters resulting from the SBSC approach described the observed $V_{\mathrm{ZS}} / X$ data less accurate than the Vesilind parameters from the dilution experiment. Also the observed correspondence was even lower for the poorly settling sludges as D and $\mathrm{P}$ compared to the well settling sludges.

\section{DISCUSSION}

The Vesilind parameters calculated from a dilution experiment $V_{\text {Zs's }}$ 'sllow a 49 layer sedimentation model to roughly describe complete experimental batch settling curves. However, when the settling dynamics observed in the experiment increase, the discrepancy between the simulation result and the data enlarges, especially at the transition between zone settling and compression phases. On this observation different comments can be made:

- When the sludge blanket reaches the bottom of the batch settler, compression phenomena start (or might start) to determine the descent of the sludge blanket in a direct way. In the compression phase sludge particles lean on each other. This is a fundamentally different situation than in the zone settling phase which is the only phenomenon characterised in the dilution experiment (Ekama et al., 1997). Here, the descent of the blanket is depending only on the equilibrium between gravitational and hydraulic friction forces.

- When the sludge blanket is low, it is also close to the conical bottom of the settling column. Some boundary processes related to the conical bottom and scraper could influence the observed processes. A hampering of the blanket movement at the bottom could be substantiated by the finding that in nearly all cases the flux curves obtained from parameter estimation on a SBSC are situated below the traditional Vesilind flux curves at the high concentration end.

The Cho model [Eq. (3)] was found to be the most effective in fitting the observed settling curves. Grijspeerdt et al. (1995) identified the Takacs model [Eq. (2)] to be the best, although they didn't include the Cho model in their comparison. Here, it has to be mentioned that the values Grijspeerdt et al. (1995) found for the Takacs $r_{\mathrm{p}}$ and $r_{\mathrm{h}}$ parameters are rather close to each other indicating that both exponential terms interfere with each other over quite a broad range. This is in contradiction with the mechanistic explanation Takacs et al. (1991) give to their model. Further, Grijspeerdt et al.
(1995), like Takacs et al. (1991) and Watts et al. (1996), used not a settling curve but a discrete solids profile as experimental data for the parameter estimation. Considering the empirical nature of the settling models it would not be surprising that the optimal model structure is depending on the nature of the experiments to be described. In this respect cross-validation of parameters between the two types of data sets as performed by Cacossa and Vaccari (1994), is certainly a task for further research.

Because data on concentration profiles were lacking, the Cho model [Eq. (3)] was cross-validated in an alternative way: it was evaluated on its ability to describe the evolution of the $V_{\mathrm{ZS}}$ as a function of the suspended solids concentration (dilution experiment). For the good settling sludges like the $\mathrm{O}$ and B sludge, the model was able to reasonably describe the observed behaviour. However, for the poorly settling sludges like $\mathrm{P}$ and $\mathrm{D}$, the Cho model [Eq. (3)] was not able to describe the trends as well as the Vesilind model [Eq. (1)]. Hence, the Vesilind model [Eq. (1)] appears to be better in describing the $V_{\mathrm{ZS}}$ obtained from dilution experiments, whereas the Cho model [Eq. (3)] is better in describing complete single batch settling curves. This points clearly towards the empirical nature of the used settling velocity models and on the fact that not all processes involved in the batch settling process are understood and taken into account.

In the past, practical identification problems associated with the estimation of parameters from a single settling curve have only been addressed to a minor extent. Cacossa and Vaccari (1994) (vaguely) mentioned that the parameters estimated by their algorithm were "somewhat sensitive to the initial guesses used". These authors stated further that reasonable parameter estimation was only possible if the sludge volume was less than half the initial volume after $60 \mathrm{~min}$ of sedimentation in their 120 $\mathrm{cm}$ tall stirred column. However, no detailed analysis was reported. In the current study identifiability problems were still encountered with curves that had a sludge volume less than a quarter of the initial one after $30 \mathrm{~min}$ of settling in a $70-\mathrm{cm}$ tall column. Vanrolleghem et al. (1996) stated that no more than three parameters in a Takacs based batch settler model could be identified from SBSC's recorded with the Settlometer. Despite these practical identifiability problems encountered while using SBSC's, the determination of Vesilind parameters through the more labour intensive, traditional dilution experiment can also be troublesome as Ekama et al. (1997) report that scattered data can be obtained.

From slow dynamic SBSC's one can obtain flux curves which are quite close to the ones obtained by a traditional dilution experiment. However, this is not always the case. For fast dynamic SBSC's the traditional Vesilind model is not able to describe 
the SBCC accurately. Here, the Cho model turns out to be the most effective one. The difference between the Cho flux curves obtained from the SBSC-approach and the traditional Vesilind flux curves can be substantial. Still, the SBSC-approach is able to distinguish between good and bad settling sludges. At present it appears the SBSC-approach is not a readily available alternative for the traditional approach as it does not give the same flux curves. If the SBSC-approach would have been successful, it would have allowed us to abandon the time consuming dilution experiments. The fact that the SBSC-approach did not turn out successful can be attributed to two major points: the impossibility of the Vesilind model to accurately describe the fast dynamic SBSC's and the identifiability problems associated with the estimation of the parameters.

It can be considered somewhat surprising that a multiple response fitting method did not solve the identifiability problem, since the traditional approach is able to yield Vesilind parameters with reasonable accuracy based on only a part of the data set used in the multiple response approach. A possible explanation for this observation could be that in the traditional approach only the zone settling behaviour is characterised while, in the multiple curve fitting approach also compression phenomena have to be incorporated. This may have led to a deterioration of the shape of the objective functional leading to the identifiability problems encountered. Additional research on this identifiability problem is certainly warranted.

In order to overcome the not yet solved identifiability problem, the experimental set up should probably be modified. In the present experimental set up, sedimentation experiments with high settling rates result in relatively few datapoints (Fig. 1). A faster detection of the sludge blanket will yield more datapoints resulting in a more detailed observation of the zone settling and transition behaviour in fast dynamic settling curves. Further it could be investigated whether extension of the sedimentation period is beneficial to the parameter estimation. Last, an experimental set up consisting of settling in batch mode followed by settling in continuous mode at well designed hydraulic loading could be an option. The realisation of such a set up will only be possible if the experimental hydraulics are not exceeding the predictive capabilities of one-dimensional settler models.

\section{CONCLUSIONS}

Parameters obtained from $V_{\mathrm{ZS}}$ in a traditional dilution experiment are able to describe batch settling curves provided the rate of descent of the sludge blanket is moderate. When the dynamics of the blanket are fast and the top of the sludge blanket reaches towards the bottom of the decanter, a significant discrepancy between the observed data and the Vesilind-based simulation results occurs. Compression phenomena and bottom boundary processes are assumed to be the major reason for this deviation. Alternative settling velocity models were tested for their ability to fit the observed settling curves. Among all models tested the one presented by Cho et al. (1993) was able to describe the complete batch settling curves best. Nevertheless, the Cho model was inferior to the Vesilind model in describing a complete set of $V_{\mathrm{ZS}^{-}}$ data obtained from a dilution experiment. The flux curves obtained from the SBSC approach differ from the ones obtained with the traditional Vesilind approach. This together with the identification problems encountered makes that the SBSC approach is not ready for practise, yet. Still, from slow dynamic settling curves with the Vesilind model flux curves can be obtained that are rather close to these traditional ones. From fast dynamic SBSC a Cho based settler model allows to distinguish between good (high sludge fluxes) and bad (low sludge fluxes) settling sludges. Different experimental set ups were suggested that might improve the practical identifiability of the settling velocity models that are at the core of the solid flux theory.

Acknowledgements - This research has been funded by a scholarship from the Flemish Institute for the Promotion of Scientific-Technological Research in the Industry (IWT). Financial support for this work was partially provided by the Belgian Fund for scientific research (F.W.O.). The authors thank their colleague Bob De Clercq for proof-reading the manuscript.

\section{REFERENCES}

Brent R. P. (1973) Algorithms for minimization without derivatives. Prentice-Hall, Englewood Cliffs, NJ.

Bye C. M. and Dold P. L. (1998) Sludge volume index settleability measures: effects of solids characteristics and test parameters. Water Environ. Res. 70, 87-93.

Cacossa K. F. and Vaccari D. A. (1994) Calibration of a compressive gravity thickening model from a single batch settling curve. Water Sci. Technol. 30(8), 107-116.

Cho S. H., Colin F., Sardin M. and Prost C. (1993) Settling velocity of activated sludge. Water Res. 27, 1237-1242.

Daigger G. T. (1995) Development of refined clarifier operating diagrams using an updated settling characteristics database. Water Environ. Res. 67, 95-100.

De heyder B., Vanrolleghem P., Van Langenhove H. and Verstraete W. (1997) Kinetic characterization of mass transfer limited biodegradation of a poorly water soluble gas in batch experiments-Necessity for multiresponse fitting. Biotechnol. Bioeng. 55(3), 511-519.

Dick R. I. and Young K. W. (1972) Analysis of thickening performance of final settling tanks. In Proceeding of the 27th Purdue Industrial Waste Conference, Lafayette, IN, ed. J. Ball, pp. 33-54.

Dupont R. and Dahl C. (1995) A one-dimensional model for a secondary settling tank including density current and short-circuiting. Water Sci. Technol. 31(2), 215-224.

Ekama G. A., Barnard J. L., Günthert F. W., Krebs P., McCorquodale J. A., Parker D. S. and Wahlberg E. J. (1997) Secondary settling tanks: theory, modeling, de- 
sign and operation. IAWQ Scientific and Technical Report No. 6, IAWQ, London.

Grijspeerdt K., Vanrolleghem P. and Verstraete W. (1995) Selection of one-dimensional sedimentation models for on-line use. Water Sci. Technol. 31, 193-204.

Jeppsson U. and Diehl S. (1996) An evaluation of a dynamic model of the secondary clarifier. Water Sci. Technol. 34(5-6), 19-26.

NBN 366.01 (1956) Wateronderzoek, Afvalwaters en Verontreinigde Waters: Zwevende Stoffen Centrifugaalmethode, 1st ed., (in Dutch).

Ong S. L. (1992) Effect of measurement error of settling velocity on secondary tank design. J. Water Pol. Con. Fed. 64, 104-110.

Otterpohl R. and Freund M. (1992) Dynamic models for clarifiers of activated sludge plants with dry and wet weather flows. Water Sci. Technol. 26(5-6), 1391-1400.

Ozinsky A. E. and Ekama G. A. (1995) Secondary settling tank modeling and design. Part 2. Linking sludge settleability measures. Water $S A$ 21, 333-349.

Stenstrom M. K. (1975) A dynamic model and computer compatible control strategies for wastewater treatment plants. Doctoral dissertation, Clemson University, USA

Takacs I., Patry G. and Nolasco D. (1991) A dynamic model of the clarification-thickening process. Water Res. 25, 1263-1271.
Vanderhasselt A. and Verstraete W. (1999) Short-term effects of additives on sludge sedimentation characteristics. Water Res. 33, 381-390.

Vanderhasselt A., Fuchs A., Vanrolleghem P., Staudinger G. and Verstraete W. (in press) Monitoring of the effects of additives on sludge separation properties by using sensors. Water Environ. Res.

Vanrolleghem P., Van Der Schueren D., Krikilion G., Grijspeerdt K., Willems P. and Verstraete W. (1996) On-line quantification of settling properties with in-sensor-experiments in an automated settlometer. Water Sci. Technol. 33(1), 37-51.

Vesilind P. A. (1968) Design of prototype thickeners from batch settling tests. Water Sewage Works 115(7), 302307.

Vitasovic Z. (1986) An integrated control strategy for the activated sludge process. Ph.D. thesis, Rice University, Houston, TX, USA

Vitasovic Z. (1989) Continuous settler operation: a dynamic model. In Dynamic modelling and expert systems in wastewater engineering, eds G. G. Patry and D. Chapman, pp. 59-81. Lewis, Chelsea, MI.

Watts R. W., Svoronos S. A. and Koopman B. (1996) One-dimensional modeling of secondary clarifiers using a concentration and feed velocity-dependent dispersion coefficient. Water Res. 33, 2112-2124. 